\title{
Impact of dietary intake and nutritional status on outcomes after liver transplantation
}

\author{
D. A. de Luis ${ }^{1}$, O. Izaola ${ }^{1}$, M. C. Veliciaa ${ }^{1,2}$, G. Sánchez Antolín ${ }^{1,2}$, F. García Pajares ${ }^{1,2}$, M. C. Terroba ${ }^{1}$ and \\ L. Cuéllar
}

${ }^{1}$ Section of Endocrinology and Nutrition. Instituto de Endocrinología y Nutrición (IEN). School of Medicine. ${ }^{2}$ Service of Digestive Diseases. Hospital Universitario Río Hortega. Valladolid, Spain

\begin{abstract}
Objective: the aim of our study was to examine, in a prospective way, whether any nutritional parameter could predict outcomes after liver transplantation.

Material and subjects: a nutritional assessment was performed in 31 consecutive patients six months prior to undergoing orthotopic liver transplantation (OLT) at a single center (Hospital U. Río Hortega) and after six months of OLT (December 2002June 2004). The nutritional evaluation included Subjective Global Assessment (SGA), Mini Nutritional Assessment test (MNA), anthropometry, laboratory tests, and three-day diet diary completed. The body composition analysis was performed by tetrapolar body electrical bioimpedance and skin folds in a standard way.

Results: our patients had an average age of $56.2 \pm 8.11$ years; weight was $72.9 \pm 15.3 \mathrm{~kg}$, and body mass index was 26.6 \pm 4 . 1 . The anthropometric evaluation showed the following data: tricipital skin fold $12.2 \pm 6.1 \mathrm{~mm}$, mid-arm circumference $24.5 \pm$ $4.1 \mathrm{~cm}$, fat-free mass $54.5 \pm 10.9 \mathrm{~kg}$, fat mass $18.4 \pm 6.5 \mathrm{~mm}$, and body water $41.4 \pm 9.1 \mathrm{~kg}$. After six months from liver transplantation, these parameters remained unchanged. Energy intake, as corrected by weight, was similar pre- and post-liver transplantation $(28.1 \pm 6 \mathrm{kcal} / \mathrm{kg}$ vs. $27.5 \pm 5.8 \mathrm{kcal} / \mathrm{kg}$ : ns). Albumin, prealbumin and transferrin improved after 6 months from transplantation. Length of stay in hospital was $22.4 \pm 14.9$ days, and length of stay in ICU was $0.7 \pm 1.7$ days. The nutritional status (SGA and MNA tests) of patients did not influence length of stay in either hospital or ICU. No intercurrent events (infections: urinary tract infection, pneumonia, and peritonitis) were recorded during the 6-month study period. Two patients died after liver transplantation (6.5\%), and 3 patients had acute rejection (9.6\%). Patients with malnutrition (SGA and MNA tests classification) showed no differences in rejection and mortality.

Conclusions: our liver transplantation population had normal nutritional status and dietary intake. Nutritional parameters showed no association with outcomes after liver transplantation. Liver transplantation improved serum protein levels and did not modify weight or dietary intake. Further studies are needed to
\end{abstract}

Recibido: 27-05-05.

Aceptado: 06-09-05.

Correspondencia: Daniel de Luis Román. Profesor Asociado de Endocrinología y Nutrición. Director Ejecutivo IEN. C/ Los Perales, 16. 47130 Valladolid.e-mail: dadluis@yahoo.com clarify the role of liver transplantation on nutritional status and of nutritional status on liver transplantation outcomes, considering different populations of patients.

Key words: Dietary intake. Liver transplantation. Nutritional status.

De Luis DA, Izaola O, Velicia MC, Sánchez Antolín G, García Pajares F, Terroba MC, Cuéllar L. Impact of dietary intake and nutritional status on outcomes after liver transplantation. Rev Esp Enferm Dig 2006; 98: 6-13.

\section{INTRODUCTION}

Chronic liver disease may be associated with malnutrition (1), the severity of which ranges from subclinical status to overt energy-protein malnutrition. In patients with decompensated cirrhosis, protein-energetic malnutrition is universal with low dietary intakes (2).

The presence of energy-protein malnutrition has been associated with increased morbidity and mortality in patients undergoing liver transplantation $(3,4)$. Preoperative malnutrition has been reported to be associated with length of stay in intensive care units (4) and mortality (5). Screening for malnutrition has been proposed as a part of liver transplantation protocols.

Developing such a strategy has been unclear due to the heterogeneity of methods to assess nutritional status. Much of the difficulty in identifying an optimal method for nutritional assessment in patients with cirrhosis arises from the fact that many of the traditionally measured parameters of nutritional status vary with severity of liver disease.

The aim of our study was to examine, in a prospective way, whether some nutritional parameters could predict clinical parameters after liver transplantation. 


\section{SUBJECTS AND METHODS}

\section{Patients}

A nutritional assessment was performed in 31 consecutive patients six months prior to undergoing orthotopic liver transplantation (OLT) at a single center (Hospital Universitario Río Hortega) and in the first nutritional revision, after six months from liver transplantation (December 2002-June 2004). Patients underwent a nutritional evaluation and a body composition analysis. The nutritional evaluation included Subjective Global Assessment (SGA), Mini Nutritional Assessment test (MNA), body composition analysis, laboratory tests, and a threeday diet diary completed. The body composition analysis was performed by tetrapolar body electrical bioimpedance and skin folds in a standard way.

\section{Weight and anthropometric data}

Body weight was measured to an accuracy of $0.5 \mathrm{~kg}$, and body mass index was computed as body weight/(height) (2). Regional changes in body mass were estimated by measuring the tricipital skin fold of the forearm, and midarm circumference (6).

\section{Body composition analysis}

Tetrapolar body electrical bioimpedance was used to determine body composition (7) using a specific equation. An electric current of $0.8 \mathrm{~mA}$ and $50 \mathrm{kHz}$ was produced by a calibrated signal generator (Biodynamics Model 310e, Seattle, WA, USA) and applied to the skin using adhesive electrodes placed on the right-side limbs. Resistance and reactance were used to calculate total body water, fat, and fat-free mass.

\section{Biochemical parameters}

A basal blood sampling was performed at the same time as the nutritional status study to measure albumin (3.5-4.5 g/dl), prealbumin $(18-28 \mathrm{mg} / \mathrm{dl})$, transferrin (250-350 $\mathrm{mg} / \mathrm{dl})$, and lymphocytes $\left(1.2-3.5 .10^{3} / \mathrm{uL}\right)$ with an autoanalyzer (Hitachi, ATM, Manheim, Ger).

\section{Dietary intake}

All patients were instructed to keep a three-day diet diary to record food, incorporating the use of food scales to enhance portion size accuracy. Records were reviewed by a dietician and analyzed with our own computer-based data-evaluation system. National composition food tables were used for reference (8). Before and after liver trans- plantation patients received an oral diet with 30 $\mathrm{cal} / \mathrm{kg} /$ day and $1 \mathrm{~g}$ protein $/ \mathrm{kg} /$ day.

\section{SGA (subjective global assessment)}

SGA was performed as described by Detsky and modified by Hasse $(9,10)$. SGA comprises a nutritional evaluation of height, current weight, weight before illness, and weight change in the previous 6 months]; nutritional history (appetite, intake, gastrointestinal symptoms); physical appearance (subjective assessment of fat loss, edema, muscle wasting, and ascites), and existing conditions (infections, encephalopathy, renal insufficiency). Based on this evaluation patients were classified into three groups; well nourished, mildly malnourished, and severely malnourished. Patients were classified into two groups: 0 (well nourished) and 1 (midly and severely malnourished).

\section{MNA (Mininutritional Assessment Test)}

The MNA test is composed of simple measurements and brief questions that can be completed in about ten minutes. These include: anthropometric measurements (weight, height, and weight loss), global assessment (six questions related to lifestyle, medication, and mobility); dietary questionnaire (eight questions related to number of meals, food and fluid intake, and autonomy of feeding), and subjective assessment (self perception of health and nutrition) (11). MNA scores distinguish between the following groups of patients: a) adequate nutritional status (MNA > 24); b) at risk of malnutrition: MNA between 17 and 23.5; and c) those with frank malnutrition: MNA < 17. Patients were classified into two groups: 0 (adequate nutritional status) and 1 (at risk of malnutrition and with overt malnutrition).

\section{Outcomes}

The following postoperative data were recorded: mortality at one year (from database of Admission Service), length of stay in ICU (days), length of stay in hospital (days), infection, acute cellular rejection (number of treated episodes). Infection was defined as any infection episode in which one or more organisms were identified, and requiring antibiotic treatment (pneumonia, urinary tract infection, and peritonitis). All episodes of acute rejection were diagnosed by biopsy.

\section{Statistical analysis}

Results were expressed as mean \pm standard deviation. The distribution of variables was analyzed using the Kol- 
mogorov-Smirnov test. Quantitative variables with normal distribution were analyzed with Student's t test. Nonparametric variables were analyzed using the MannWhitney U test. Discrete variables were analyzed with the Chi square test, with Yates correction as necessary, and Fisher's test. Pearson and Spearman test were used to study correlation among variables. A p-value below 0.05 was considered statistically significant.

\section{RESULTS}

\section{Baseline evaluation}

Thirty-one patients were enrolled in the study. Table I shows the demographic characteristics of the studied population. Our patients were predominantly males with a normal body mass index and weight.

\begin{tabular}{lc}
\multicolumn{2}{l}{ Table I. Characteristics of patients with liver transplantation } \\
at baseline
\end{tabular}

\section{Anthropometric measurements and dietary intake}

Anthropometric evaluation showed the following data: tricipital skin fold $12.2 \pm 6.1 \mathrm{~mm}$, mid-arm circumference $24.5 \pm 4.1 \mathrm{~cm}$, fat-free mass $54.5 \pm 10.9 \mathrm{~kg}$, and fat mass $18.4 \pm 6.5 \mathrm{~kg}$. After six months of liver transplantation, these parameters remained unchanged (Table II). No changes were detected in dietary intake for 6 months after transplantation (Table II). Energy intake, as corrected by weight, was similar (pre OLT: $28.1 \pm 6 \mathrm{cal} / \mathrm{kg} v s$. post OLT: $27.5 \pm 5.8 \mathrm{cal} / \mathrm{kg}$ : ns).

\section{Biochemical parameters}

Albumin, prealbumin and transferrin improved after 6 months from transplantation (Table III).
Table II. Anthropometric parameters and dietary intake

\begin{tabular}{lccc}
\hline & Basal time & Six months & $p$ \\
\hline Weight (kg) & $72.9 \pm 15.3$ & $72.4 \pm 15.1$ & ns \\
BMI (kg/m²) & $26.6 \pm 15.3$ & $26.4 \pm 3.9$ & ns \\
Tricipital skinfold (mm) & $12.2 \pm 6.1$ & $11.6 \pm 4.8$ & ns \\
Mid-arm circumference (cm) & $24.5 \pm 4.1$ & $23.7 \pm 2.9$ & ns \\
Fat-free mass (kg) & $54.5 \pm 10.9$ & $53.9 \pm 10.2$ & ns \\
Fat mass (kg) & $18.4 \pm 6.5$ & $18.5 \pm 6.3$ & ns \\
Body water (kg) & $41.4 \pm 9.1$ & $40.7 \pm 8.3$ & ns \\
Calories per day & $2017 \pm 474$ & $1993 \pm 445$ & ns \\
Carbohydrates (g/day) & $233.8 \pm 58.1$ & $1993 \pm 445$ & ns \\
TCV 46.2\% & & & \\
Proteins (g/day) & $94.1 \pm 28.8$ & $94.2 \pm 18.9$ & ns \\
TCV 18.6\% & & & \\
Lipids (g/day) & $81.9 \pm 41.6$ & $79.8 \pm 22.9$ & ns \\
TCV 35.1\% & & & \\
\hline
\end{tabular}

TCV: total caloric value.

Table III. Biochemical parameters

\begin{tabular}{lccc}
\hline Parameters & Baseline & Six months & $\mathrm{p}$ \\
\hline Albumin $(\mathrm{g} / \mathrm{L})$ & $3.2 \pm 0.7$ & $3.8 \pm 0.6$ & $<0.05$ \\
Prealbumin $(\mathrm{mg} / \mathrm{dl})$ & $8.6 \pm 4.7$ & $19.5 \pm 8.8$ & $<0.05$ \\
Transferrin $(\mathrm{mg} / \mathrm{dl})$ & $190.8 \pm 17.9$ & $231.25 \pm 21.1$ & $<0.05$ \\
\hline
\end{tabular}

\section{Length of stay, intercurrent illness, and mortality}

Length of stay in hospital was $22.4 \pm 14.9$ days, and length of stay in ICU was $0.7 \pm 1.7$ days. No intercurrent events (infections: urinary tract infection, pneumonia, and peritonitis) were recorded during the 6-month study period. The nutritional status of patients did not influence length of stay in hospital or ICU. This analysis was performed with SGA and MNA tests.

A total of 2 patients died after liver transplantation $(6.4 \%)$, and 3 patients had acute rejection $(9.6 \%)$. Patients with malnutrition (SGA and MNA tests classification) showed no differences in acute rejection and mortality.

Isolated parameters such as albumin, prealbumin, transferrin, weight, fat-free mass, and BMI did not correlate with any outcome parameters.

\section{DISCUSSION}

In our prospective study of nutritional status, dietary intake and outcome after liver transplantation, we did not find any associations. No single parameter of nutritional status or dietary intake was consistently associated with ICU stays, as Figueiredo et al. showed in their study (12).

The differences between the findings of some authors and ours are likely to be due to a combination of factors. 
One-year mortality and frequency of infection was lower in our study when compared to other studies $(3,13)$. Although the basis of the higher mortality seen in previous studies is not clear, differences in patient populations are apparent. The main characteristics of our population were different from those of other studies (well nourished status, male sex, and alcoholic cirrhosis). Before and after liver transplantation, weight and body mass index had normal values, with no modification in body water.

Acute cellular rejection is a common complication after liver transplantation, seen in $60-70 \%$ of liver transplant recipients (14). In our study, acute rejection had a low incidence. This low incidence resulted in no association between nutritional status and rejection in our patients -perhaps a type-II error played a major role in our results. Baghthgate et al. (15) have detected that the only significant predictor of decreased likelihood of acute graft rejection in those patients was a decreased mid-arm muscle circumference. Our patients had a better mid-arm circumference and a lower incidence of rejection.

Several parameters that are frequently used to assess nutritional status in patients with cirrhosis were not useful in predicting outcomes. Similar to other investigators, we explored the possibility of combining several tests into an index of nutritional status (16-19). We were not able to identify any combination of parameters, such as the SGA test or MNA test, capable of identifying patients at increased risk of adverse postrasplant outcomes. Our results were similar to those reported by Abbott et al. (20); however other authors found a positive association between SGA test scores and length of stay (21). Perhaps the normal nutritional status of our patients pre-transplantation produced this lack of association.

Adequate oral intake would reduce the need for artificial nutrition in these patients. There are several studies supporting the view that a modified eating pattern with four to seven small meals, including at least one lateevening carbohydrate-rich snack, improves nitrogen economy and partially reverses abnormal substrate oxidation in cirrhotic patients (17). However, the feasibility of these dietary modifications in cirrhosis is not well established, since there is only limited information about spontaneous energy intake patterns in these patients. In our population, energy intake (2000 cal/day) and macronutrient distribution had adequate values. When Madden et al. (22) measured resting energy expenditures (REE) by indirect calorimetry in 100 cirrhotic patients, mean REE was $1660 \pm 337 \mathrm{cal} / \mathrm{day}$. Le Cornu et al. (23) showed that pretrasplant enteral supplementation did not increase nutritional intake and had no effect on outcome after liver transplantation. The still-insufficiently known relationship between nutritional status and extent of liver dysfunction is of great interest. In our country few studies have evaluated this area (24), and our group is the first to show data on liver transplantation in Spain.

In conclusion, our liver pre-transplantation population had a normal nutritional status and dietary intake. Nutri- tional parameters showed no association with outcomes after liver transplantation, perhaps due to this normal nutritional status. Liver transplantation improved seric protein levels and did not modify weight and dietary intake in our sample. Further studies are needed to clarify the role of liver transplantation on nutritional status, and of nutritional status on liver transplantation, considering the various populations of patients.

\section{REFERENCES}

1. Gopalan S, Saran S Sengupta R. Practicalities of nutrition support in chronic liver disease. Curr Op in Clin Nutr and Metab Care 2000; 3 : 227-9.

2. DiCecco S, Wieners E, Wiesner R, Southborn P, Plevak D. Assessment of nutritional status of patients with end-stage liver disease undergoing liver transplantation. Mayo Clin Proc 1989; 64: 95.

3. Selberg O, Bottcher J, Tusch G, Pichlmayr R, Henkel E, Muller M. Identification of high and low risk patients before liver transplantation: a prospective cohort study of nutritional and metabolic parameters in 150 patients. Hepatology 1997; 25: 652-8.

4. Ricci P, Therneau T, Malinchoc M. A prognostic model for the outcome of liver transplantation in patients with cholestatic liver disease. Hepatology 1997; 25: 672-5.

5. Lautz H, Selberg O, Korber M, Muller M. Protein-calorie malnutrition in liver cirrhosis. Clin Invest 1992; 70: 478-82.

6. Pemberton C, Moxness K, German M, Nelson J, Gastineau C. Mayo Clinic Diet Manual, $6^{\text {th }}$ ed. Toronto: BC Decker, 1988. p. 230-5.

7. Kyle UG, Genton L, Mentha H, Nicod L, Slosman D, Pichard C. Reliable bioelectrical impedance analysis estimate of fat-free mass in liver, lung and heart transplant patients. J Parent Enteral Nutr 2001; 25: 45-51.

8. Mataix J, Mañas M. Tablas de composición de alimentos españoles. $3^{a}$ ed. Ed: University of Granada, 1998. p. 1-167.

9. Detsky AS, McLaughlin JR, Baker JP. What is subjective global assessment of nutritional status? JPEN 1987; 11: 8-13.

10. Hasse J, Strong S, Gorman M, Liepa G. Subjective global assessment: alternative nutrition-assessment technique for liver transplant candidates. Nutrition 1993; 9: 339-42.

11. Guigoz Y, Vellas B, Garry PJ. Assessing the nutritional status of the elderly: the Mini Nutritional Assessment as part of the geriatric evaluation. Nutr Rev 1996; 54: s59-65.

12. Figueiredo F, Rolland Dickson E, Pasha T, Kasparova P, Therneau T, Malinchoc M. Impact of nutritional status on outcomes after liver transplantation. Transplantation 2000; 70: 1347-52.

13. Muller M, Lautz H, Plogmann B, Burger M, Korber J, Schmidt F. Energy expenditure and substrate oxidation in patients with cirrhosis: the impact of cause, clinical standing and nutritional state. Hepatology 1992; 15: 782-7.

14. Wiesner RH, Demetris AJ, Belle SH. Acute hepatic allograft rejection: incidence, risk factors, and impact on outcome. Hepatology 1998; 28: 638-44.

15. Bathgate AJ, Hynd P, Sommerville D, Hayes PC. The prediction of acute cellular rejection in orthotopic liver trasnplantation. Liver Transpl Surg 1999; 5: 475-9.

16. Merli M, Riggio O, Dally L, PINC. Does malnutrition affect survival in cirrhosis? Hepatology 1996; 23: 1041-446.

17. Harvey KB, Moldawer LL, Bristian BR, Blackburn GL. Biological measures for the formulation of a hospital prognostic index. Am J Clin Nutr 1981; 34: 2013-7.

18. Harrison J, McKiernan J, Neureberg JM. A prospective study on the effect of recipient nutritional status on outcome in liver transplantation. Transplant Int 1997; 10: 369-73.

19. Chang WK, Chao YC, Tang HS. Effects of extra-carbohydrate supplementation in the late evening on energy expenditure and substrate oxidation in patients with liver cirrhosis. JPEN 1997; 21: 96-9.

20. Abbott WJ, Thomson A, Steadman C, Gatton ML, Bothwell C, Kerlin P. Child Pugh class, nutritional indicators and early transplant outcomes. Hepatogastroenterology 2001; 48: 823-7. 
21. Stephenson GR, Moretti EW, El Moalem H, Clavien PA. Malnutrition in liver transplant patients: preoperative subjective global assessment is predictive of outcome after liver transplantation. Transplantation 2001; 72: 666-70.

22. Madden AM, Morgan MY.Resting expenditure should be measured in patients with cirrhosis, not predicted. Hepatology 1999; 30: 65564.
23. Le Cornu KA, McKiernan FJ, Kapadia SA, Neuberger JM. A prospective randomized study of preoperative nutritional supplementation in patients awaiting elective orthotopic liver transplantation. Transplantation 2000; 69: 1364-9.

24. Pinedo S, Solano D, de la Villa FM, Bilbao Goitia P. Protein-calorie malnutrition and degree of hepatic failure in chronic hepatopathy. Rev Esp Enferm Dig 1993; 84: 381-5. 